\title{
Evaluation method to improve standard setting in engineering courses-A study
}

\author{
S.Julius Fusic ${ }^{1}$, M.Rishwana ${ }^{1}$, P.R.K.Swathilakshmi ${ }^{1}$, D.Kavitha ${ }^{2}$ \\ ${ }^{1}$ Department of Mechatronics Engineering, Thiagarajar College of engineering, Madurai. \\ ${ }^{2}$ Department of Electrical and Electronics Engineering, Thiagarajar college of engineering, Madurai.
}

\author{
${ }^{1}$ sjf@tce.edu \\ ${ }^{2}$ dkavitha@tce.edu
}

\begin{abstract}
The older system of education depends only on the theory, which could lag the students to understand the concept properly. So, they feel hard to apply it in their daily life. The introduction of CDIO syllabus helps the students in the application of concepts and also motivates them to do the hands on model. The way of assessment is done through Bloom's taxonomy and Rubric's Tool. There are four common types of assessment that are being used in today life. They are formative, bench mark, diagnostic and summative. They all serve instinct purposes and should work together in order to make up a comprehensive or balanced assessment program. TCEians follow CDIO education system, as to make the students concentrate in both theory and practical. The CDIO stands for Conceive Design, Implement, operate. The initiative created made the education framework that drive engineering fundamentals set in the context of conceiving, designing, implementing and operating real-world systems and products. The CDIO based education approach uses active learning tools, such as group projects and problem-based learning, to better equip engineering students with technical knowledge as well as communication and professional skills. This system also helps the poor students to come up with their latent (inbuilt) ability.
\end{abstract}

Keywords: Peer teaching, CDIO syllabus, assessment, Gamifying Techniques.

\section{Introduction}

Assessment is not only validating the student activity but it also stressed as learning technique. When students are able to see how they are doing in the class, they are able to determine whether or not they understand the course material. Assessment can also motivate students throughout the education career. If students know they are doing poorly, they may begin to work harder. Several definitions such as formative assessment, informative assessment, Teacher enquiry, Quantitative \& Qualitative research, assessment through gamifying and assessment for learning have to be practiced. The main purpose of valuation is to improve students learning and teaching as both respond to the information it provides. Assessment for learning is a process that arises out of the interaction between teaching and learning.

[1] An entrepreneur Sebastian Thrun detailed that "The Individualization of learning fundamentally redefines the role of assessment. We believe that assessment is an integral and essential part of teaching and learning process.
It should encourage pupils to reflect, enquire and preserve, as they strive to be successful learners".

[2] According to Fenton, "Assessment is the collection of relevant information that may be relied on for making decisions. Evaluation is the application of a standard and a decision-making system to assessment data to produce judgments about the amount and adequacy of the learning that has taken place."

[3] David Ausubel suggested that the most important factor influencing learning is what the learner already knows, that teachers should ascertain this, and teach accordingly.

[4] Guskey said that one to one tutoring is so effective because tutor is able to identify the mistakes, misunderstanding of the students and clarify them immediately.

[5]Randy Elliot bennet says that students could gain interest if the subjects were taught in the form of games and he further adds that they should be assessed based on that. This improves their skills

\section{Assessment and its Theories}

The word "Assessment" means the process of checking the effectiveness of sequences of instrumental activities. Bloom convinced that teaching a student individually is a good method but later on, such method of one to one tutoring seems unhelpful. Natriello, in 1987 proposed another theory involving 8 major stages like voicing the importance of evaluation, tasks given to students, monitoring and setting grades for their performance, sampling and appraising on their works, providing feedback to them and keeping an eye on the output of their performance. Also, it has been told that the use of traditional criteria of validity and reliability will no longer benefits but at the end we get puzzled by the question," Which criteria can be assessed?"

To solve the above question, the assessment cycle is the provided answer. The building blocks of the assessment cycle involves selection of assessment tasks, applying criteria, monitoring, giving grades to the performance and finally giving a review of them, as said by

\section{S.Julius fusic \\ Department of Mechatronics, Thiagarajar College of Engineering, Madurai. \\ sjf@tce.edu}

Dylan William. They cover almost the major reason of assessment development. A more specific criteria or representativeness, a meaningful content, complicity in fewer rates and finally it speaks about the coverage of the 
content. The assessment cycle is useful and it is used to analyze, think and implement it. Informal formative assessment is all about class room activities of teacherstudent like classroom educational conversation, active questioning and participation of students, teacher's observation on the student's immense knowledge, interest and his understanding. This type of environment provides higher order cognitive skills. This one among the efficient method.

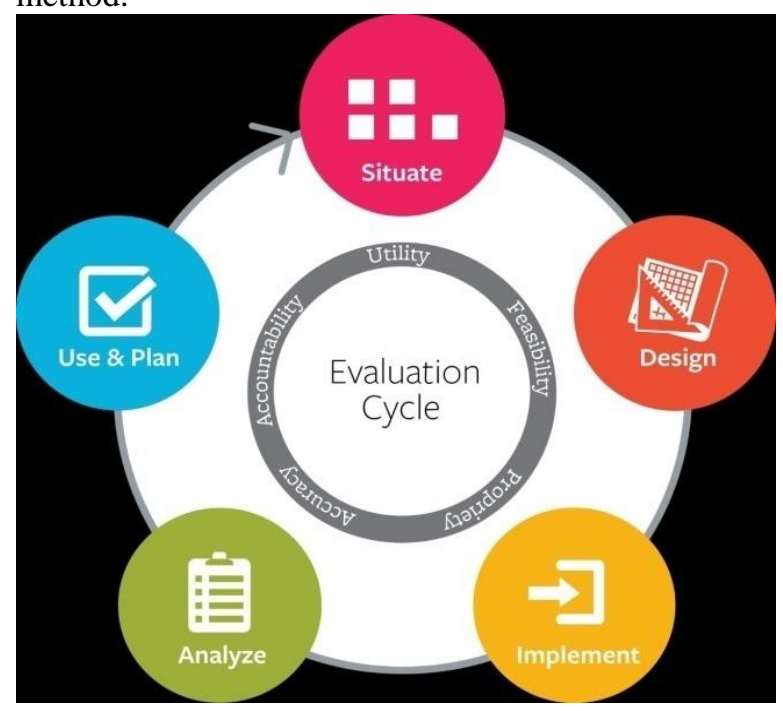

Fig. 1 Flow diagram for assessment cycle.

\section{Validation of teaching and learning questionnaire}

In an Institution, it is highly important to know about the learning environment and its influence on the student's life. The most common two type of learning practices done in all institutes or either role or deep level learning. Role learning is a surface level learning where the students are made to memorize their concept in study material and reproduce that in exam, this is not appreciable. The knowledge obtained from this method is short lived whereas in deep level learning, activities are also helpful based on the concept taught in exams. Institution follow this system may produce better results than the former getting an idea about the subject is more essential than simply memorizing them.

Researches on formative assessment and feedback are reinterpreted to know whether the process can make a student to self-taught. Intelligent self-regulation needs the student to set certain goals and aims in their life, in academic field, specific targets, criteria, standards and other external reference points helps to define goals over the last two decades, the teacher cordite feedback about the student's and their higher education in a different way such that the student's, why they themselves are begin to create and construct the own skills of knowledge even though, selflearning is a good method the teachers must monitored the students performance and if they are interested then they must help them with their own ideas to enhance student's knowledge.
It is highly expected that the teachers will use technologies and model to explain the concept to student's in a better way. Sitting in class room and listening will sure increase the knowledge but making them go to class will enhance the practical knowledge. Such learning environment is really appreciable. Teacher's quality is set to improved by increased class localization of training, giving them professional opportunities, and school improvement etc., is advised,

\section{A. Formative assessment}

It is an assessment for learning day by day, learning needs of student's of trying to provide it to them in efficient way.

\section{B. Summative assessment:}

Listening the achievements and the monitoring the performance of a single student at the end of the year. It is an approach found in late 1980s to focus on the ability of teachers in their own professional practice.

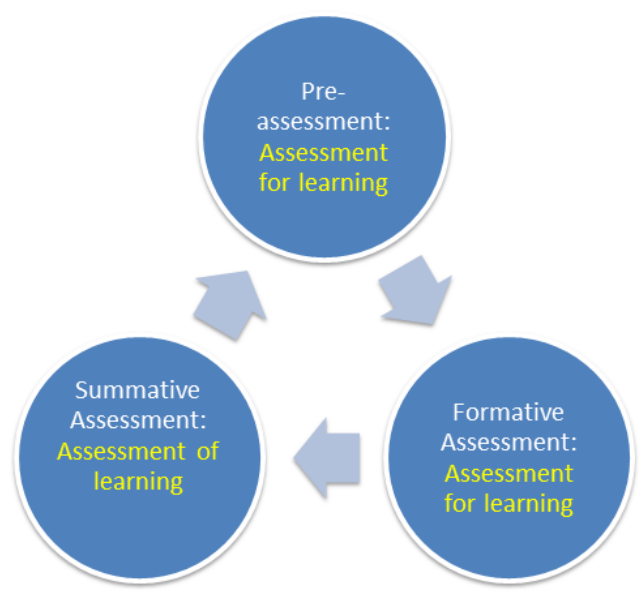

Fig. 2 Flow diagram of different types of assessments.

\section{Research:}

It is an activity which helps the human minds to come out with unknown things that is not yet discovered.

EVALUATION:

It is defined as the process which is done to find about the advantage, worth, values of something or product of the process.

\section{Assessment:}

It is nothing but a process done to bring out the balance to an individual or a group activity. By doing so, the intensity level of a person's knowledge can be accurately calculated.

Similarities in the above three:

- Data analysis

- Role of researches

- The final production of report and result 


\section{- $\quad$ Ethics}

Difference in the above three:

- Purpose

- Audience

- Focus

\section{Education gamifying formative assessment}

Randy Elliot Bennet explored about the gamifying and gave the following meaning,

What is gamifying?

This is nothing but the use of gaming ideas and game design techniques for the better understanding of the students. Thus, they get so exited and also they will learn their subjects. Intrinsically and extrinsically, a person gets motivated and helshe performs their tasks in a proper and correct manner like teacher expected.

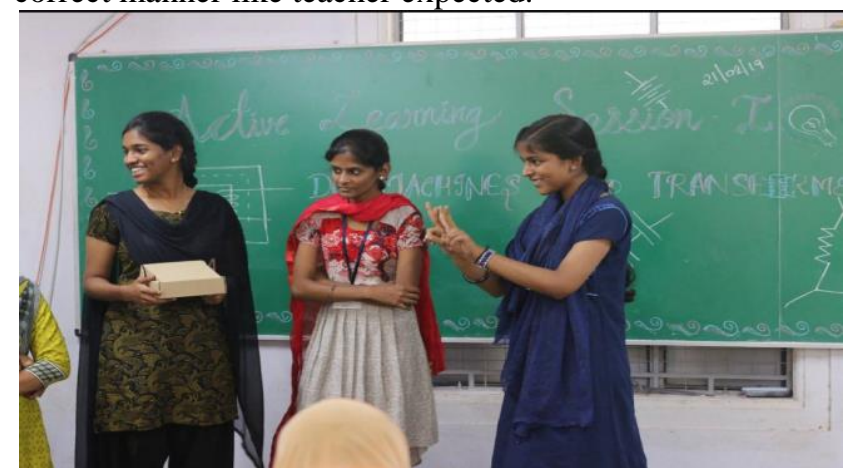

Fig.3. Using games to understand the concepts.

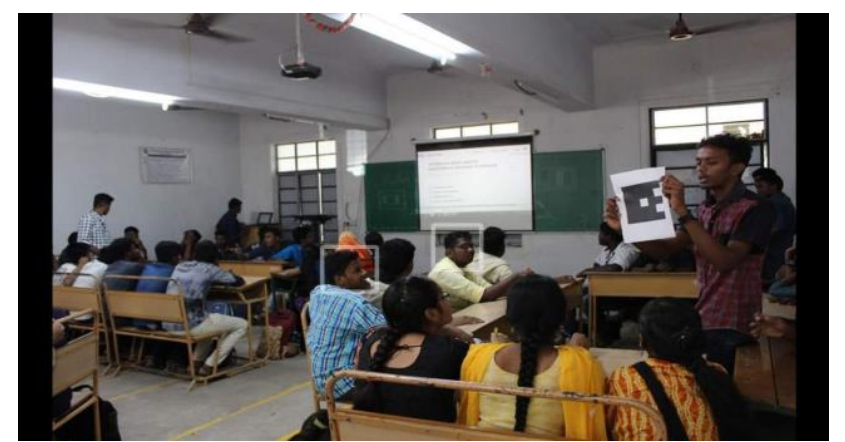

Fig.4.Assessing through games using plicker software tool.

Plickers is an awesome assessment tool that you can use to quickly assess your students knowledge through multiple choice questions.

Use of plickers:

Student - involvement, fun, bring attention, chance to express the views individually, Feel of personal touch to the teacher directly, highly advantageous to reserved students.

Concept wise question - more wrong. Not understood by the student. Repeat the concept. Individual report to analyze each student to provide suitable motivation Personal care. Measure Cognitive level of the students. Involvement in the class. If not showing answer, easily found out.
A. Project reverse grading

According to Amanda M. Marcotte,

The objective of this grading is,

- All students will get full marks for 1 day,

- The slow and fast learners are not categorized

- Now, they are told to retain their marks

- They are told to participate actively in class room discussion after doing their presentation, projects and exhibit learning skills. This is also considered as a method for the betterment of the students.

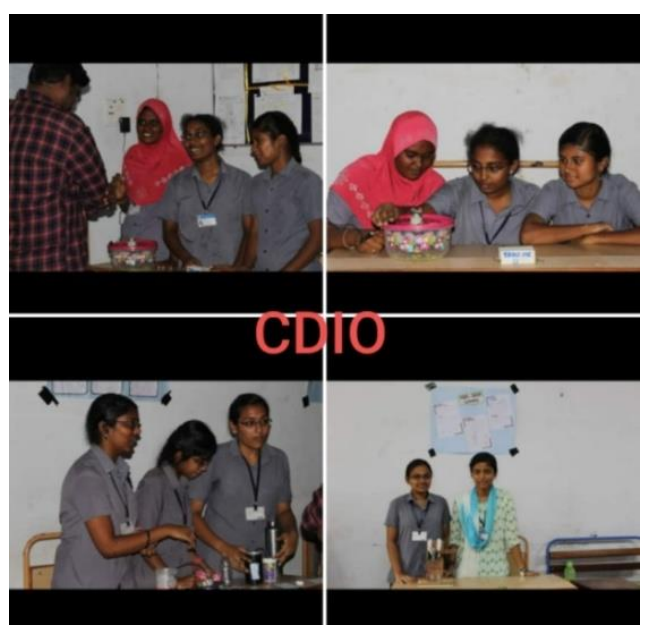

Fig.5. Applying the learned concepts as demonstration.

\section{Student's evaluations of teaching quality}

Suitably Daniela Feistier\& Tobias Richter, explained that,

By using the multilevel models, the teaching quality of the Institution students are noted. Students are made to evaluate lectures and seminars over the past 3 years, yielding a total of 4224 data points. The substantial variance components of teachers and courses suggest reliability.

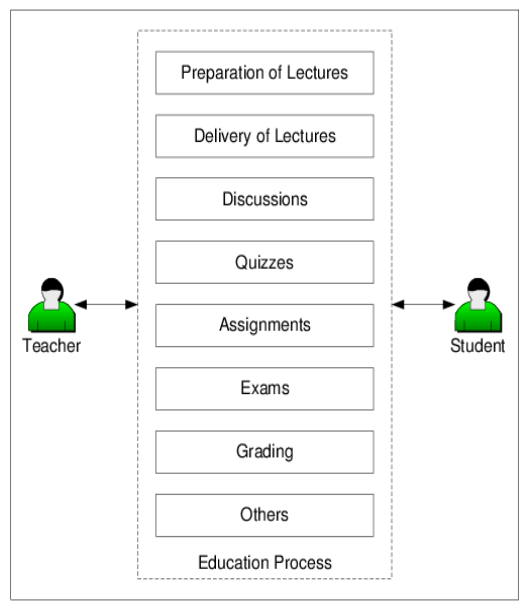

Fig.6.Concept of evaluating each other.

Isadore Newman and Carolyn Ridenour, said that Qualitative and quantitative research have philosophical 
roots in the naturalistic and positivists philosophies respectively. The debate is about what reality is and whether it is measurable or not. Finally the qualitative research is followed from Sir Isaac Newton and Albert Einstein that the theory is derived from the practical experiments. The interactive continuum model in this review serves as a kind of framework directed toward both those needs. In 1996, Professor Douglas and in 1993 Gertz believed that the existence of multiple realities that are available in different individuals are equally valid. Kuhn's study of methodology draws him to leave the physics and become a historian of science.

Likewise Jade hunter discussed that over the last 5 decades, Teacher Inquiry has been applied on teaching field covering a wide range of subjects and teacher-oriented practices.

Teachers should have been known about the blogging and other social apps, hence to come out with bright ideas.

Aims and strategy of the project

Our starting point was that any effort to understand and then improve the tensions between formative and summative assessments should start with an attempt to explore and develop the quality of teachers' summative assessments. We therefore formulated a project that combined both intervention and research that would explore the process of that intervention. The specific aims of the research were to study how teachers understand validity, how they formulate their summative assessment practices in the light of that understanding, and how that understanding might be challenged and developed.

Activities and methods

The sources of research data were as follows:

- Classroom observations of summative assessment events, including the guidance, questioning and other help given to students.

- Detailed records, observations and audio recordings of in-school, and the subsequent inter-school, moderation meetings

- Transcribed individual interviews with the head of department and one other departmental teacher in each of the English and mathematics departments in each school

Teachers' lack of skills and confidence in assessment Overall, we found that at the outset of our work the teachers' practices, even those under their control, lacked both the rig our and the comparability that would be required, both intra- and inter-school.

\section{Summative Assessment by Teachers}

As per the research, John Biggs concludes that teachers routinely sum up what their students have learned. The skill of summarizing is therefore integral to instruction and to informing instructional practice. Teachers sum up in a multiplicity of ways, from an informal comment on a particular piece of work to a formal grade generalizing about overall performance. There are numerous possible reasons why information about the performance of students might be needed by someone other than the teacher and the student. These purposes will be referred to herein three broad categories:

- Reporting on the individual student to other teachers in the same school, to another school, or to a parent/guardian;

- Reporting on individual performance as part of a process leading to the student being awarded an external qualification;

- Reporting on the performance of groups of students to supply aggregate data which managers of the school system will use to monitor the performance of teachers and schools.

Four crucial features of summative assessment by teachers:

- it is systematic, occurring within a system;

- it requires teachers to draw inferences from the evidence they have of student learning;

- it calls for teachers to exercise their judgment; and

- It involves some form of report on student achievement.

\section{TASK SPECIFICATION}

The tasks should, in principle, reflect the educational outcomes of the course of study.

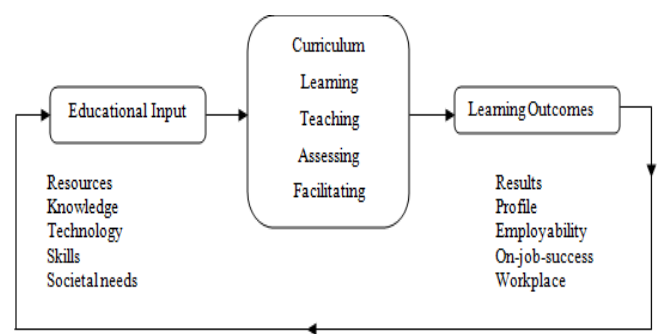

Fig.7. Flow diagram of educational outcomes.

There is evidence from a number of contexts of significant variability in the way teachers draw inferences and make judgments, suggesting a need for research into the deep structures of teacher judgments and the underlying conceptualizations.

In a social and cultural context where teachers are trusted to exercise their judgment of student performance, there are two essential features if such systems are to be designed and implemented effectively.

In a system must be compatible with the use(s) that will be made of the student-performance data produced by that

System. Second, a sophisticated infrastructure is required if large-scale systems are to realize the potential benefits, in terms of both validity and reliability, of extending the involvement of teachers beyond the use of their judgment For internal reporting purposes.

\section{Assessment for learning-Formative assessment}


The key elements obtained from the literature study as follows,

1. Development of smart classroom to implement learning assessment tools.

2. Establishment of mapping between the learning and course outcome in periodic way.

3. Varied instruction method to satisfy the student expectation.

4. Innovation approaches to assess the students knowledge, skills and psychomotor.

5. Student performance feedback assessment and proper remedial measures to improve student action.

6. Ensure student involvement in activities and learning.

\section{A. Policy implications:}

Policy principles of formative assessment to promote wider, deeper and more sustained practice are to:

1. The prime focus was teaching and learning practice.

2. Interpret the summative and formative often in individual courses.

3. The formative use of collection of data during class and home activity at every instant.

4. Training invests and supports to be done for formative initiation.

5. Encourage innovation among students like makers space.

6. Create opportunities in research, policy and practice among facilitators.

The four suggestions consolidated from a range of literature, including:

1. Guidelines and principles for teaching and learning based on practitioner wisdom and experience.

2. Debates on how values and goals for adult LLN learning - such as learner self-determination and

3. Autonomy, or democratic learning environments should shape classroom relationships and approaches.

The introduction of surveys and feedbacks of learners and instructor view on effective improvement of learning and teaching.

\section{Case studies and classroom observations}

Three experimental groups (EGs) of strength of 40 students are selected and the selection of group is in heterogeneous mode in each class. Plickers are used continuously in 8 periods for EG1 which covers a complete module- Design of synchronous sequential circuits. The same questions designed for learning by doing (LBD) were asked to the students of EG2 and responses were noted in class notes and assessed based on the observation of the teacher. LBD questions are provided as assignments for EG3. The performance of the three EGs in the summative assessment is recorded as shown in Figure 7. The summative assessment questions are different but based on LBD questions.

\section{A. T test Analysis and results:}

One tailed unpaired t test results:

Hypothesis: There is no significant difference in the performance of the students
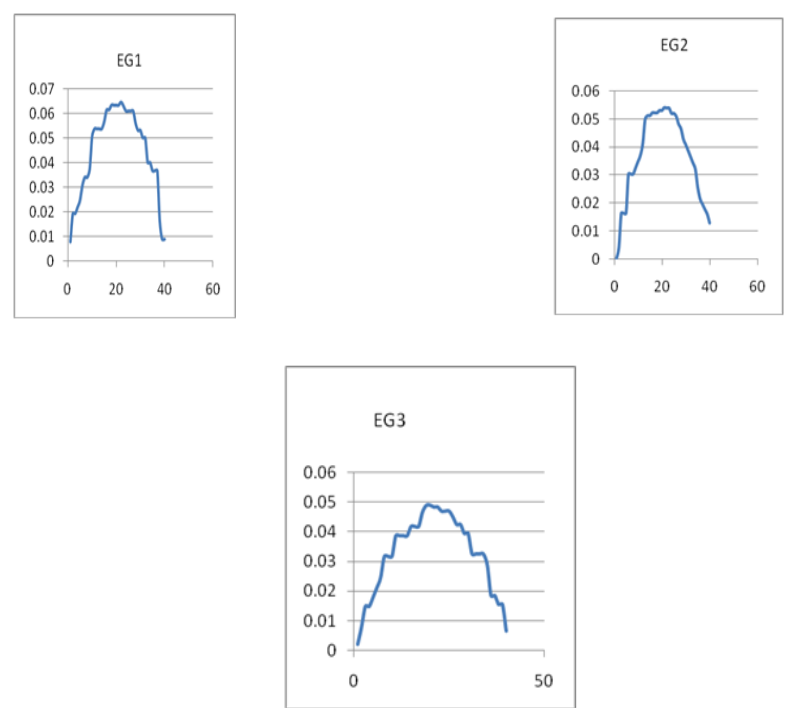

Fig.7. Distribution of marks obtained by three experimental groups.

Table 1: Standard deviation and Mean value for each group.

\begin{tabular}{|l|l|l|l|}
\hline & EG1 & EG2 & EG3 \\
\hline MEAN & 37.1375 & 35.94871795 & 30.1 \\
\hline SD & 6.220301234 & 7.391135223 & 8.68184076 \\
\hline
\end{tabular}

Table 2: T test results compared for EG1, EG2 and EG3

\begin{tabular}{|l|l|l|}
\hline S.No & Compared groups & Ttest - value \\
\hline 1 & EG1 \& EG2 & 0.221132219 \\
\hline 2 & EG2 \& EG3 & 0.000925242 \\
\hline 3 & EG3 \&EG1 & 4.29865 E-05 \\
\hline
\end{tabular}

B. Inference:

Use of plickers for EG1 doesn't have much significance on performance when compared to EG2 but have much significance with EG3. Hence technology does not guarantee improvement in performance but it offers a comfortable and convenient way of handling and assessing records. This statement is attained as a result of survey taken from the students and teachers.

Learning by doing is very important and it is understand from the performance variations which have significant difference with respect to EG3.

C. Feedback from faculty:

Case 1: Individual addressing of students become possible.

Case 2: Faculty requires to spend more time to assess individual performance.

Case 3: Time slot is required additionally to address the course outcome since assignments answers needed to be discussed in the next class which includes refreshing the previous day content and some students didn't complete the assignment.

D. Feedback from students:

Case 1: No way to ignore. Should be active in class. It is fun to show the card.

Case 2: needs to be active in the class. Slightly bored by the learning by doing assessments. 
Case 3: Class is passive. Assignments are easily copied. Felt sleepy sometimes.

The monitoring and activity evaluation of particular assessment tools which including portfolios, recognition of prior learning, ICT programmes. The fact is that knowledge on the impact of the different approaches to teaching and assessment is limited in the adult LLN sector. Without better knowledge of what works (and what doesn't work), it will be difficult to attract much-needed funding, or to develop effective practices across the sector. The good news is that the existing research base (including research on the generic methods of formative assessment, as well as practitioner wisdom) provides clear direction for future research and development. The stakes of not taking on this challenge will be high for communities as well as learners.

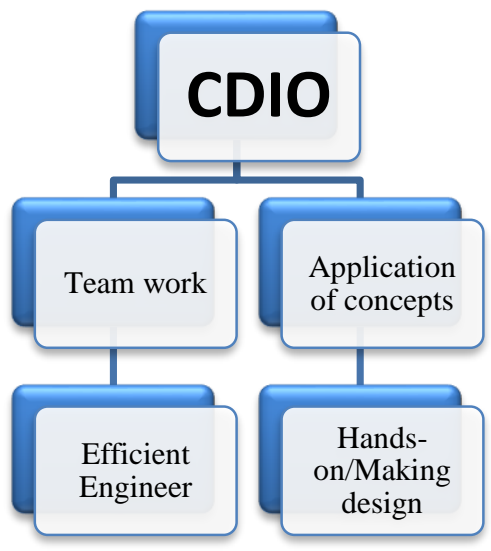

Fig.8. Outcomes of CDIO

\section{Conclusion}

In this paper, we have concluded an idea that learning can be improved by peer activities. Due to implementation of games and activities as part of curriculum, the assessment marks was be improved as shown in case study. Students took more time for individualised learning which reduce their skill over the course. Direct interaction between students promoted through active learning activities made them to learn concepts more enthusiasm. The peer teaching voluntarily developed the interest in specific topics among students. Therefore, through CDIO they develop skills in organising and planning learning activities, working collaboratively with others, giving and receiving feedback, and evaluating their own learning. The overview of assessment is the systematic, ongoing process of gathering and interpreting evidence of a student learning to determine if a program is meeting its learning goals and then using that information to improve the program. So, we come to a conclusion that assessment is a key component of learning.

\section{REFERENCES}

[1] Wynne Harlen and Mary James (1997) “Assessment and Learning: differences and relationships between formative and summative assessment", Scottish council for research in education, 4:3,365-379.
[2] Eleanor Hawe and Helen Dixon (2016) "Assessment for learning: a catalyst for students self regulation", Assessment and Evaluation in Higher Education, 10.1080 .

[3] William L.Sanders and Sandra P Horn(1998) "Implication for Educational Evaluation and Research”,University of Tennessee Value added research and Assessment Centre, Vol 12:3 247-256.

[4] Kovanovi'c, V., Gaševi'c, D., Hatala, M., \& Siemens, G. (2017). "A novel model of cognitive presence assessment using automated learning analytics methods" SRI Education.

[5] David J. Nicol \& Debra Macfarlane-Dick (2006): "Assessment andIts learning": Studies in Higher Education, 31:2, 199-218.

[6] Rosemary Luckin, Wilma Clark, Katerina Avramides, Jade Hunter \& MartiOliver (2016):" TI to support technology-enhanced formative assessment": a review of the literature to inform a new method, Interactive Learning Environments.

[7] S. Julius Fusic; N. Anandh; I. Leando; M. Manimegalan, (2018) "Peer Teaching Among UG Students", IEEE Tenth International Conference on Technology for Education (T4E).

[8] Newman, Isadore and Ridenour,Carolyn (1998) "Qualitative and Quantitative Research Methods": Exploring the interactive Continum, Educational Leadership faculty publication.

[9] Mike Mimirinis (2018) "Qualitative differences in academics "concepts of e-assessment, \& Evaluation in Higher Education,

[10] Daniela Feistauer \& Tobias Richter (2016): How reliable are students 'evaluations of teaching quality? A variance components approach, Assessment \& Evaluation in Higher Education. 